\title{
Changes with altitude of stand structure of temperate forests on Mount Norikura, central Japan
}

Yutaka Miyajima · Koichi Takahashi*

Department of Biology, Faculty of Science, Shinshu University, Matsumoto 390-8621, Japan

*: corresponding author:

e-mail: koichit@gipac.shinshu-u.ac.jp, tel: 0263.37.2533, fax: 0263.37.2560

Type of contribution: original article

Subject area and field: Biology and ecology (vegetation dynamics)

Page count: 16

Number of tables: 0

Number of figures: 4 
Abstract Altitudinal changes in stand structure were studied at 10 sites between $800 \mathrm{~m}$ and $2500 \mathrm{~m}$ a.s.1. in temperate forests on Mount Norikura $\left(36^{\circ} 06^{\prime} \mathrm{N}, 137^{\circ} 33^{\prime} \mathrm{E}, 3026 \mathrm{~m}\right.$ a.s.l.) in central Japan. Vegetation of this altitudinal range was roughly classified asa subalpine coniferous forest zone between $1600 \mathrm{~m}$ and $2500 \mathrm{~m}$ a.s.1. the timberline. The frequency distribution of trunk height was a L-shaped pattern at $800 \mathrm{~m}$ a.s.l. and changed to flat pattern with increasing altitude up to $2000 \mathrm{~m}$ a.s.1. it changed to L-shaped pattern again from $2000 \mathrm{~m}$ to $2500 \mathrm{~m}$ a.s.1. This altitudinal change frequency distribution of trunk height warelated to the altitudinal change maximum trunk height. The maximum trunk height did not change with altitude between $800 \mathrm{~m}$ and $2000 \mathrm{~m}$ a.s.1., but it decreased from $2000 \mathrm{~m}$ to $2500 \mathrm{~m}$ a.s.1. Mechanical damage of conifer trunks and branches was not observed between $800 \mathrm{~m}$ and $2000 \mathrm{~m}$ a.s.l.

However, the proportion of damaged trees increased from $2000 \mathrm{~m}$ to $2500 \mathrm{~m}$ a.s.1., suggesting thatsubalpine conifers cannot grow in height near the timberline due to mechanical damage. Therefore, the increase number of small trees from $2000 \mathrm{~m}$ a.s.1. to the timberline was to less developed canopy structure, i.e., small trees can grow without shading by canopy trees. This study suggests that the timberline formation.

Keywords mechanical damage $\cdot$ stand structure $\cdot$ timberline $\cdot$ trunk height

\section{Introduction}

vailable energy for plant growth, influences forest vegetation. Many researchers have 
examined the altitudinal changes in forest vegetation in various forest ecosystems such as tropical forests, subtropical forests, warm-temperate forests, temperate forests and boreal forests (Takahashi 1962; Yamada 1977; Ohsawa 1984; Kirkpatrick and Hassall 1985; Kojima 1994; Lieberman et al. 1996; Tang and Ohsawa 1997; Kamijo et al. 2001). For example, in central Japan,, forest vegetation changes from evergreen broad-leaved forests at low altitude to deciduous broad-leaved forests at middle altitude, and to evergreen coniferous forests at high altitude (Yoshino 1978). Takahashi et al. (2003, 2005) showed that theTakahashi et al. $(2003,2005)$ showed that growth of Betula ermanii differently respondeded to climatic conditions at its upper and lower distribution limits in a subalpine forest on Mount Norikura, central Japan. High summer temperature coupled with less precipitation increases the growth of Betula ermanii at its upper distribution limit (i.e., the timberline) because of cool climate in this high altitude, while the high temperature coupled with less precipitation decreases the growth at its lower distribution limit probably because of the increase of drought stress (Takahashi et al. 2003, 2005). Thus, tree regeneration may be different along altitudinal gradients even within a same vegetation zone such as subalpine forest zone. However, little information is available for altitudinal changes in forest regeneration.

The stand structure of forests is thought to reflect regeneration processes. From the shape of size frequency distribution, we can suggest regeneration patterns. Unimodal and bimodal distributions suggest a discontinuous regeneration pattern, while L-shaped distributions suggest a continuous regeneration pattern (Veblen 1986; Kohyama and Hotta 1990; Masaki et al. 1992). At the individual-tree level, the growth in trunk height more decreases with increasing altitude, as compared with trunk 
diameter (Aiba and Kitayama 1999), partly because strong wind inhibits the growth in height. Thus, a comparison of trunk height-diameter allometry among different altitudes shows the altitudinal changes in the growth traits (e.g., Wang et al. 2006). In addition, recently, some researchers showed that many trees in timberlines suffered severe mechanical damage due to strong wind and heavy snow (Kajimoto et al. 2002, 2004; Seki et al. 2005). Therefore, stand structural characteristics provide useful information to elucidate the altitudinal changes in regeneration. Although a few studies have been made on the altitudinal change in stand structure in tropical forests (e.g., Aiba and Kitayama 1999), little is known in temperate forests. Therefore, this studyinvestigateded the changes in stand structure including the proportion of damaged trees along an altitudinal gradient on Mount Norikura in central Japan.

\section{Materials and methods}

Study site

This study was carried out on the east slope of Mount Norikura $\left(36^{\circ} 06^{\prime} \mathrm{N}, 137^{\circ} 33^{\prime} \mathrm{E}\right.$, $3026 \mathrm{~m}$ above sea level) in central Japan. Mean annual temperature recorded at Nagawa Weather Station (1068 $\mathrm{m}$ a.s.1., approximately $12 \mathrm{~km}$ in horizontal distance from the summit) was $8.4^{\circ} \mathrm{C}$ in 2003 . Mean monthly temperatures in the coldest month of January and the hottest month of August were -4.2 and $20.3^{\circ} \mathrm{C}$, respectively. Annual sum of precipitation was $2206 \mathrm{~mm}$.

Three major vegetation zones of tree species were recognized between $800 \mathrm{~m}$ 
and $3000 \mathrm{~m}$ a.s.1. on Mount Norikura, i.e., the montane deciduous broad-leaved forest zone between $800 \mathrm{~m}$ and $1600 \mathrm{~m}$ a.s.1., the subalpine coniferous forest zone between $1600 \mathrm{~m}$ and $2500 \mathrm{~m}$ a.s.l. and the alpine dwarf pine Pinus pumila scrub zone between $2500 \mathrm{~m}$ and $3000 \mathrm{~m}$ a.s.1. The timberline was located at about $2500 \mathrm{~m}$ a.s.l. on the examined east slope of Mount Norikura (Takahashi 2003). Kira's warmth index (WI) also often used to express relationships between thermal conditions and vegetation (Kira 1948). WI expresses the approximate effective heat for plant growth. WI is calculated as $\sum\left(m_{t}-5\right)$, where $m_{t}$ is mean monthly temperature above $5^{\circ} \mathrm{C}$. The WI was estimated as $48.5^{\circ} \mathrm{C}$ months at $1600 \mathrm{~m}$ a.s.l. (the upper distribution limit of the montane broad-leaved forest zone) and $21.9^{\circ} \mathrm{C}$ months at $2500 \mathrm{~m}$ a.s.l. (the timberline) on Mount Norikura by using decadal temperature data (1994 to 2003) in Nagawa Weather Station with a lapse rate of $-0.55^{\circ} \mathrm{C}$ for each $+100 \mathrm{~m}$ in altitude.

Vegetation between $800 \mathrm{~m}$ and $1600 \mathrm{~m}$ a.s.1. was partly subjected to anthropogenic effects, but this study was done at the sites without the anthropogenic effects. Anthropogenic effects on vegetation were negligible from $1600 \mathrm{~m}$ a.s.l. to the summit. Dominant species were deciduous broad-leaved Zeikova serrata, Juglans mandshurica var. sachalinensis, Lindera praecox at $800 \mathrm{~m}$ a.s.1., deciduous broad-leaved Quercus crispula, Castanea crenata, Betula platyphylla var. japonica at 1400 m a.s.1., evergreen conifer Abies veitchii, Tsuga diversifolia at $1600 \mathrm{~m}-2000 \mathrm{~m}$ a.s.1., evergreen conifer Abies mariesii, deciduous broad-leaved Betula ermanii, Sorbus matsumurana at $2200 \mathrm{~m}-2500 \mathrm{~m}$ a.s.1.

Plant nomenclature was followed by Shimizu (1997). 
Field measurements

Stand strucuture was surveyed at total 10 sites at $100 \sim 300 \mathrm{~m}$ altitudinal intervals between $800 \mathrm{~m}$ and $2500 \mathrm{~m}$ a.s.1. in 2003 and 2004. Two belt transects $(5 \times 50 \mathrm{~m})$ were established at a representative vegetation site of each altitude. Species was identified, trunk height and diameter at breast height $(\mathrm{DBH})$ were investigated for all trees taller than $1.3 \mathrm{~m}$. Mechanical damage of trunks and branches was checked for conifers, according to Kajimoto et al. (2002). The mechanical damage includes flagged shape of crowns, tip dieback, broken stem and canopy anomaly with branch-lacking layers (cf. Kajimoto et al. 2002), The mechanical damage is caused by strong wind and heavy snow in winter. In terms of, windblown snow and ice abrade leaves near timberlines, and then cause winter desiccation (Wardle 1968, 1985; Hadley and Smith 1983, 1986; Maruta 1996). As a result, wind-exposed trunks and branches are damaged or die (Arseneault and Payette 1992; Pereg and Payette 1998). Mechanical damage was not investigated for broad-leaved tree species because of the difficulty of identification of the its character.

The following expanded allometry was employed to describe the relationship between trunk height $(H, \mathrm{~m})$ and $\mathrm{DBH}(D, \mathrm{~cm})$,

$\frac{1}{H}=\frac{1}{A \cdot D^{h}}+\frac{1}{H^{*}}$

where $A(\mathrm{~m} / \mathrm{cm}), h$ (dimensionless) and $H^{*}(\mathrm{~m})$ are constants. $H^{*}$ is the expected maximum trunk height. These three constants were estimated by an iterative nonlinear regression that minimizes the sum of squires of residuals (RSS). 


\section{Results}

The total basal area of trees taller than $1.3 \mathrm{~m}$ and the observed observed maximum DBH did not decrease with increasing altitude (Fig. 1a, c). Although the observed observed maximum trunk height did not change with increasing altitude between $800 \mathrm{~m}$ and 2000 m a.s.1., it largely decreased from $2000 \mathrm{~m}$ to $2500 \mathrm{~m}$ a.s.1. (Fig. 1d). The tree density consistently decreased from $800 \mathrm{~m}$ to $2000 \mathrm{~m}$ a.s.l. (Fig. 1b). However, the tree density increased from $2000 \mathrm{~m}$ to $2500 \mathrm{~m}$ a.s.1. (Fig. 1b). This increase of the tree density corresponded with the reduction of the maximum trunk height (Fig. 1d).

The frequency distribution of trunk height was a L-shaped pattern at $800 \mathrm{~m}$ a.s.1. (Fig. 2a). In this altitude, many small understory tree species present in the deciduous broad-leaved forestexisted. Of these species, a deciduous broad-leaved Lindera praecox was the most dominanton the understory. The frequency distribution of trunk height changed to the flat-shaped pattern with increasing altitude up to $2000 \mathrm{~m}$ a.s.l. (Fig. $2 \mathrm{a}-\mathrm{g}$ ). This reduction at small size classes was mainly due to reduction of small understory tree species. Small trees of trees of canopy and subcanopy tree species were not frequent in the upper zone of the montane forest (1100 $\mathrm{m}$ and $1400 \mathrm{~m}$ a.s.1.) and in the subalpine forest up to $2000 \mathrm{~m}$ a.s.1. (Fig. $2 \mathrm{c}-\mathrm{g}$ ). Especially at the lower distribution limit (1600 m a.s.l.) of subalpine coniferous forest, there were few small understory tree species and the frequency distribution of canopy and subcanopy tree species was a flat pattern (Fig. 2e). However, the number of trees shorter than $5 \mathrm{~m}$ increased from $2200 \mathrm{~m}$ to $2500 \mathrm{~m}$ a.s.1., and the size structure became to the an 
L-shaped pattern again (Fig. $2 \mathrm{~h}-\mathrm{i}$ ). A deciduous broad-leaved Sorbus matsumurana and a dwarf pine Pinus pumila were dominant small tree species at the upper zone of the subalpine forest (2400 $\mathrm{m}$ and $2500 \mathrm{~m}$ a.s.1.).

were shown in Figure 3. Expanded allometry fitted well to the relationship between DBH and trunk height at the 10 altitudes between $800 \mathrm{~m}$ and $2500 \mathrm{~m}$ a.s.1. (data not shown). Trunk heights at DBH 10, 20, 30 and $40 \mathrm{~cm}$ were estimated by the expanded allometric regression of each altitude. Although trunk height at a given DBH increased from $800 \mathrm{~m}$ to $1400 \mathrm{~m}$ a.s.1., it decreased from $1400 \mathrm{~m}$ to $2500 \mathrm{~m}$ a.s.1. (Fig. 3). The difference in of the estimated trunk height between DBH $10 \mathrm{~cm}$ and $40 \mathrm{~cm}$ was about $14 \mathrm{~m}$ at $1600 \mathrm{~m}$ a.s.l. that was the lower distribution limit of the subalpine coniferous forest dominated by Abies mariesii and A. veitchii (Fig. 3). However, this difference was only $5 \mathrm{~m}$ at $2500 \mathrm{~m}$ a.s.1. that was the upper distribution limit of the subalpine coniferous forest (i.e., timberline) (Fig. 3). Therefore, the growth in trunk height near the timberline was considerably inhibited, compared with the growth in trunk diameter.

Mechanical damage of conifer trunks and branches was not observed between $800 \mathrm{~m}$ and $2000 \mathrm{~m}$ a.s.l. (Fig. 1d). However, the proportion of damaged trees increased from $2000 \mathrm{~m}$ to $2500 \mathrm{~m}$ a.s.1. (Fig. 1d). This increase was consistent with the reduction of the maximum trunk height in these altitudes (Fig. 1d). Fig. 4 shows relationships between trunk height and DBH of conifers at $2200 \mathrm{~m}, 2400 \mathrm{~m}$ and $2500 \mathrm{~m}$ a.s.1. Taller trees tended to be damaged at higher altitudes. Thus, trees could not grow in height in height near the timberline. 


\section{Discussion}

In this temperate forest, the maximum DBH did not decrease with increasing altitude throughout the examined altitudinal range from $800 \mathrm{~m}$ to $2500 \mathrm{~m}$ a.s.l. of the timberline. The maximum trunk height also did not change between $800 \mathrm{~m}$ and $2000 \mathrm{~m}$ a.s.1., but decreased markedly from $2000 \mathrm{~m}$ a.s.1. to $2500 \mathrm{~m}$ a.s.l. at the timberline. In contrast, the maximum trunk height and DBH decrease continuously with increasing altitude in tropical forests (Yamada 1977; Ohsawa 1995; Aiba and Kitayama 1999). Reduction of air temperature with increasing altitude means the reduction of available energy for trees in tropical forests in non-seasonal environments, which reduces the maximum tree size in higher altitudes. On the contrary, Ohsawa (1995) showed that Ohsawa (1995) showed that the maximum trunk height did not change with increasing altitude, except for near the timberline, in temperate forests, like as shown in this study. Available energy for tree growth undoubtedly decreases with increasing altitude not only in tropical forests but also in temperate forests. However, the rate of decrease of rate of available energy for plants is lower in temperate forests than in tropical forests (Ohsawa 1995). Therefore, forest biomass and the maximum tree height do not decrease with increasing altitude, except for timberlines, in temperate forests.

Generally, the thermal conditions of many timberlines in the world correspond to WI $15^{\circ} \mathrm{C}$ months (Ohsawa 1990). However, timberlines in Japan often locates in the altitudes of WI greater than $15^{\circ} \mathrm{C}$ months (Okitsu and Ito 1984a). Actually, WI is $21.9^{\circ} \mathrm{C}$ months at the timberline on Mount Norikura, and therefore, Miyajima et al. (unpublished manuscript) it is suggested thatt altitudinal position of the timberline on 
Mount Norikura is not regulated by thermal condition alone. In this study, the maximum tree height decreased sharply near the timberline, and this decrease corresponded with the occurrence of mechanical damage of trunks and branches. Okitsu and Ito (1989) reported that Wind velocity is considerably high in high altitudes, which causes the mechanical damages trees by winter desiccation (Warren Wilson 1959; Hadley and Smith 1983, 1986). alpine dwarf pine Pinus pumila dominates above the timberline. was However, Pinus pumila is hardly damaged by winter winter desiccation (Maruta et al. 1996), because it is completely covered with snow in winter (Okitsu and Ito 1984b). Accordingly, not onlyit is suggested that thermal conditions during the growing season but also strong wind in winter largely affect the altitudinal position of timberline on Mount Norikura.

The frequency distribution of trunk height changed from the L-shaped pattern at $800 \mathrm{~m}$ a.s.1. to the a flat-shaped pattern at $2000 \mathrm{~m}$ a.s.1. However, the number of small trees increased from $2000 \mathrm{~m}$ to $2500 \mathrm{~m}$ a.s.l. of the timberline, and the size structure shifted to the L-shaped pattern again. The increase of small trees corresponded with the reduction of the maximum trunk height. The reduction of small trees from $800 \mathrm{~m}$ to $2000 \mathrm{~m}$ a.s.l. is probably ascribed to the reduction of available energy for the photosynthetic production of small understory trees. Photosynthetic production of understory trees is mainly limited by shortage of light resource, irrespective of altitudes. In addition, the growth period is shorter and air temperature during the growth period is lower with increasing altitude. Photosynthetic rate of plants is generally temperature dependent, and low temperatures reduce the photosynthetic production of alpine and subalpine plants (DeLucia and Smith 1987; Körner 1999). Therefore, the combined 
stress (dark and cool conditions, and short growth period) is disproportionately more harmful for the photosynthetic production of understory trees at higher altitudes compared with canopy trees in sunlit conditions, which probably reduces the growth and survival of understory trees at higher altitudes. On the contrary, the increase of small trees from $2000 \mathrm{~m}$ to $2500 \mathrm{~m}$ a.s.l. of the timberline corresponded with the increase of the mechanical damage of trunks and branches. Reduced development of the canopy layer, due to the increas of trunk broken, brought about much light for small trees, which enabled small trees to grow and survive, which in turn brought about the L-shaped pattern near the timberline. Therefore, it is suggested that the stand structural change with increasing altitude was caused by the combined stress for understory trees and by the increase of the mechanical damage of trunks.

This study concluded that (1) the size structural changes along the altitudinal gradient were caused by the combined stress (dark and cool conditions, and short growth period) for understory trees and by the increase of the mechanical damage, which influenced the altitudinal change in the regeneration pattern, (2) not only thermal conditions during the growing season but also the mechanical damage in winter possibly determine the altitudinal position of the timberline. Therefore, this study suggests that the mechanical damage is the causal factor affecting the altitudinal changes in the regeneration pattern and determining the altitudinal position of the timberline. 
Acknowledgements This study was partially supported by a grant from the Ministry of Education, Culture, Sports, Science and Technology, Japan to KT (No. 15710007).

\section{Literature cited}

Aiba S, Kitayama K (1999) Structure, composition and species diversity in an altitude-substrate matrix of rain forest tree communities on Mount Kinabalu, Borneo. Plant Ecol 140:139-157

Arseneault D, Payette S (1992) A postfire shift from lichen-spruce to lichen-tundra vegetation at tree line. Ecology 73:1067-1081

DeLucia EH, Smith WK (1987) Air and soil temperature limitations on photosynthesis in Engelmann spruce during summer. Can J For Res 17:527-533

Hadley JL, Smith WK (1983) Influence of wind exposure on needle desiccation and mortality for timberline conifers in Wyoming, U.S.A. Arc Alp Res 15:127-135

Hadley JL, Smith WK (1986) Wind effects on needles of timberline conifers: seasonal influence on mortality. Ecology 67:12-19

Kajimoto T, Daimaru H, Okamoto T, Otani T, Onodera H (2004) Effects of snow avalanche disturbance on regeneration of subalpine Abies mariesii forest, northern Japan. Arc Antarc Alp Res 36:436-445

Kajimoto T, Seki T, Ikeda S, Daimaru H, Okamoto T, Onodera H (2002) Effects of snowfall fluctuation on tree growth and establishment of subalpine Abies mariesii near upper forest-limit of Mt. Yumori, northern Japan. Arc Antarc Alp Res 34:191-200 
Kamijo T, Isogai T, Hoshino Y, Hakamada H (2001) Altitudinal zonation and structure of warm-temperate forests on Mikura-jima Island, Izu Islands, Japan. Veg Sci $18: 13-22$

Kira T (1948) On the altitudinal arrangement of climatic zones in Japan (in Japanese). Kanti-Nogaku 2:143-173

Kirkpatrick JB, Hassall DC (1985) The vegetation and flora along an altitudinal transect through tropical forest at Mount Korobaba, Fiji. NZ J Bot 23:33-46

Kohyama T, Hotta M (1990) Significance of allometry in tropical saplings. Funct Ecol $4: 515-521$

Kojima S (1994) Vegetation and environment of Betula ermanii forest on the Kamchatka Peninsula (in Japanese). Jpn J Ecol 44:49-59

Körner C (1999) Alpine Plant Life. Springer, Berlin

Lieberman D, Lieberman M, Peralata R, Hartshorn GS (1996) Tropical forest structure and composition on a large-scale altitudinal gradient in Costa Rica. J Ecol $84: 137-152$

Maruta E (1996) Winter water relations of timberline larch (Larix leptolepis Gord.) on Mt. Fuji. Trees 11:119-126

Maruta E, Nakano T, Ishida A, Iida H, Masuzawa T (1996) Water relations of Pinus pumila in the snow melting season at the alpine region of Mt. Tateyama. Proc. Nat. Inst. Polar Res. Symp. Polar Biol. 9:335-342

Masaki T, Suzuki W, Niiyama K, Iida S, Tanaka H, Nakashizuka T (1992) Community structure of a species-rich temperate forest, Ogawa Forest Reserve, central Japan. Vegetatio 98:97-111 
Ohsawa M (1984) Differentiation of vegetation zones and species strategies in the subalpine region of Mt. Fuji. Vegetatio 57:15-52

Ohsawa M (1990) An interpretation of latitudinal patterns of forest limits in south and east Asian mountains. J Ecol 78:326-339

Ohsawa M (1995) Latitudinal comparison of altitudinal changes in forest structure, leaf-type, and species richness in humid monsoon Asia. Vegetatio 121:3-10

Okitsu S, Ito K (1984a) The relation of forest limit to the WI 15 in mountains of Hokkaido (in Japanese). Jpn J Ecol 34:341-346

Okitsu S, Ito K (1984b) Vegetation dynamics of the Siberian dwarf pine (Pinus pumila Regel) in the Taisetsu mountain range, Hokkaido, Japan. Vegetatio 58:105-113

Pereg D, Payette S (1998) Development of black spruce growth forms at treeline. Plant Ecol 138:137-147

Seki T, Kajimoto T, Sugita H, Daimaru H, Ikeda S, Okamoto T (2005) Mechanical damage on Abies mariesii trees buried below the snowpack. Arc Antarc Alp Res $37: 34-40$

Shimizu T (1997) Flora of Nagano Prefecture (in Japanese). Shinano Mainichi Shinbunsha, Nagano

Takahashi K (1962) Studies on vertical distribution of the forest in middle Honshu (in Japanese). Bull Gov For Exp St 142:1-171

Takahashi K (2003) Effects of climatic conditions on shoot elongation of alpine dwarf pine (Pinus pumila) at its upper and lower altitudinal limits in central Japan. Arc Antarc Alp Res 35:1-7

Takahashi K, Azuma H, Yasue K (2003) Effects of climate on the radial growth of tree 
species in the upper and lower distribution limits of an altitudinal ecotone on Mount Norikura, central Japan. Ecol Res 18:549-558

Takahashi K, Tokumitsu Y, Yasue K (2005) Climatic factors affecting the tree-ring width of Betula ermanii at the timberline on Mount Norikura, central Japan. Ecol Res 20:445-451

Tang CQ, Ohsawa M (1997) Zonal transition of evergreen, deciduous, and coniferous forests along the altitudinal gradient on a humid subtropical mountain, Mt. Emei, Sichuan, China. Plant Ecol 133:63-78

Veblen TT (1986) Age and size structure of subalpine forests in the Colorado Front Range. Bull Torrey Bot Club 113:225-240

Wang X, Fang J, Tang Z, Zhu B (2006) Climatic control of primary forest structure and DBH-height allometry in Northeast China. For Ecol Manage 234:264-274

Wardle P (1968) Engelmann spruce (Picea engelmannii Engel.) at its upper limits on the Front Range, Colorado. Ecology 49:483-495

Wardle P (1985) New Zealand timberlines. 1. Growth and survival of native and introduced tree species in the Craigiebun Range, Canterbury. NZ J Bot $23: 219-234$

Warren Wilson J (1959) Notes on wind and its effects in arctic-alpine vegetation. J Ecol 47:415-427

Yamada I (1977) Forest ecological studies of the montane forest of Mt. Pangrango, West Java. IV. Floristic composition along the altitude. South East Studies 15:226-254

Yoshino MM (1978) Altitudinal vegetation belts of Japan with special reference to 
climatic conditions. Arc Alp Res 10:449-456

\section{Figure legends}

Fig. 1. Altitudinal changes in (a) the total basal area, (b) tree density ( $>1.3 \mathrm{~m}$ tall), (c) the observed observed maximum DBH, (d) the observed observed maximum trunk height (solid circle) and proportion of trees with mechanical damage of trunks and branches (open circle) at 10 sites between $800 \mathrm{~m}$ and $2500 \mathrm{~m}$ a.s.1. on Mount Norikura in central Japan.

Fig. 2. Altitudinal changes in the frequency distribution of trunk height at 10 sites between $800 \mathrm{~m}$ and $2500 \mathrm{~m}$ a.s.1. on Mount Norikura in central Japan. Dark and light shaded bars indicate canopy and subcanopy tree species and small understory tree species, respectively. Note that ordinate scales of (i) and (j) are different from those of (a) $\sim$ (h).

Fig. 3. Altitudinal changes in tree heights of DBH $10 \mathrm{~cm}$ (solid circle), $20 \mathrm{~cm}$ (open circle), $30 \mathrm{~cm}$ (solid triangle) and $40 \mathrm{~cm}$ (open triangle) between $800 \mathrm{~m}$ and $2500 \mathrm{~m}$ a.s.1. on Mount Norikura in central Japan. Tree height of each DBH at each altitude was 
estimated from the expanded allometric regression.

Fig. 4. Relationships between trunk height and diameter at breast height of conifers at (a) $2200 \mathrm{~m}$, (b) $2400 \mathrm{~m}$ and (c) $2500 \mathrm{~m}$ a.s.1. on Mount Norikura in central Japan. Solid and open circles represent trees with and without mechanical damages, respectively. 

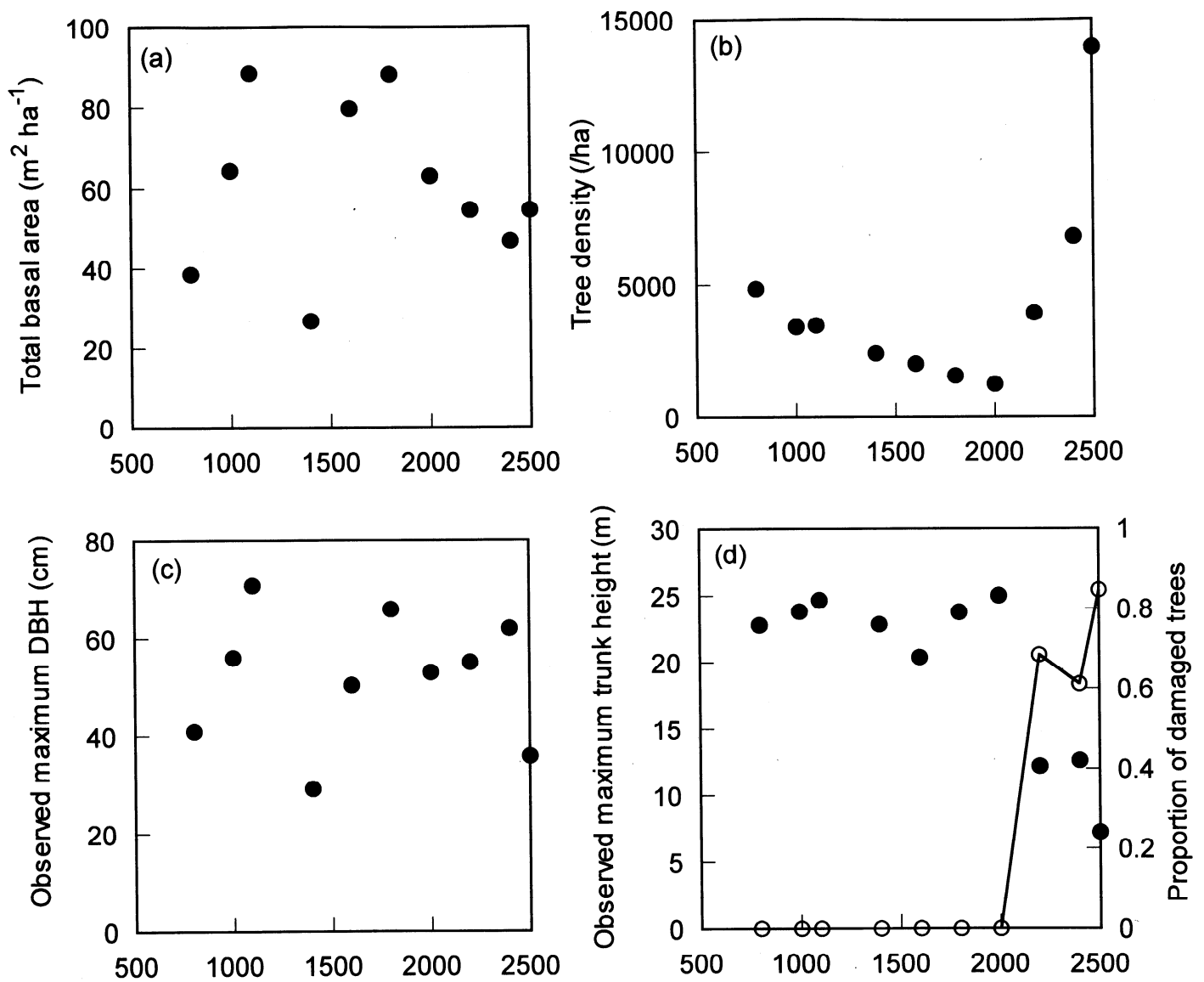

Altitude (m)

Fig. 1. 


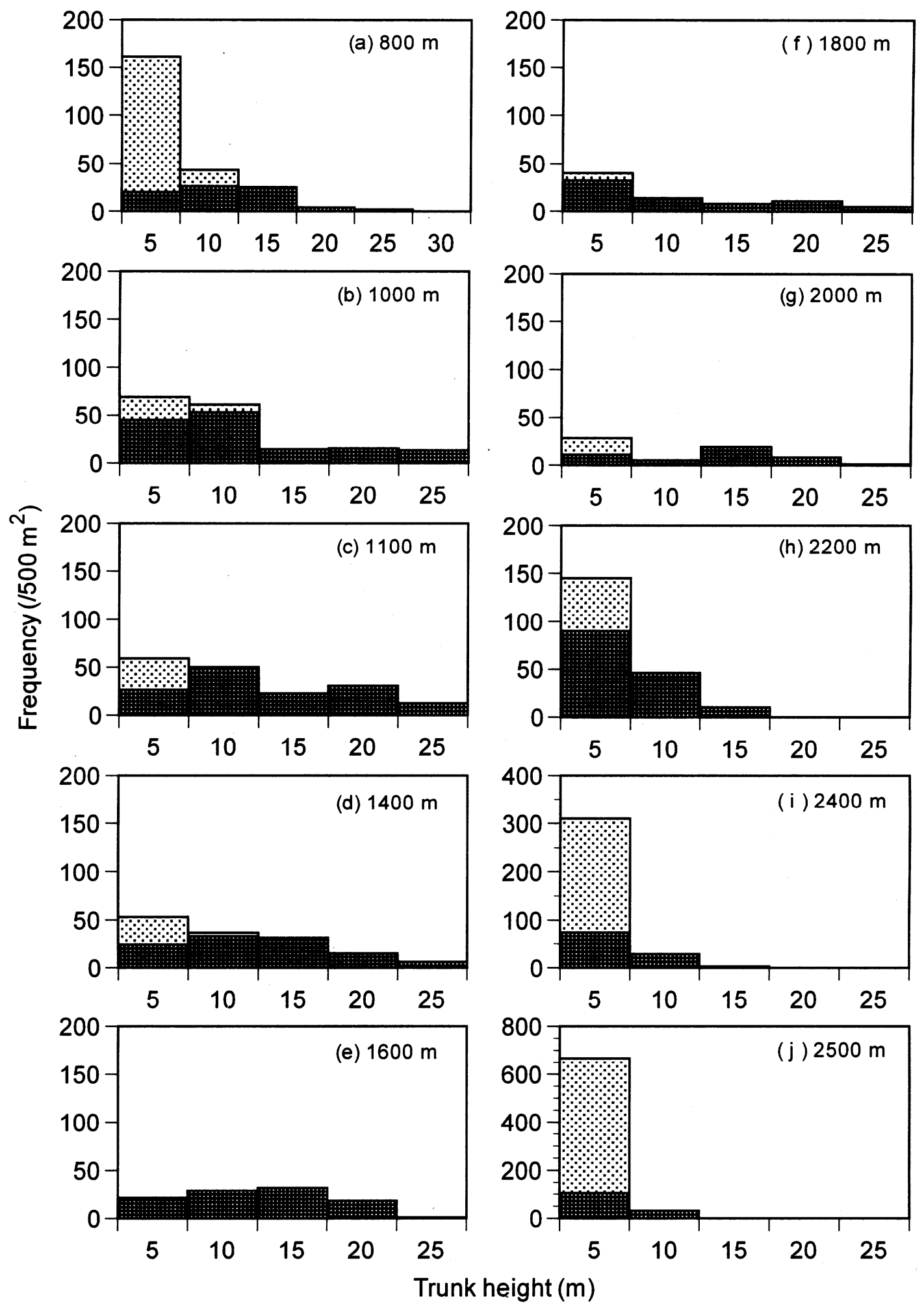

Fig. 2. 


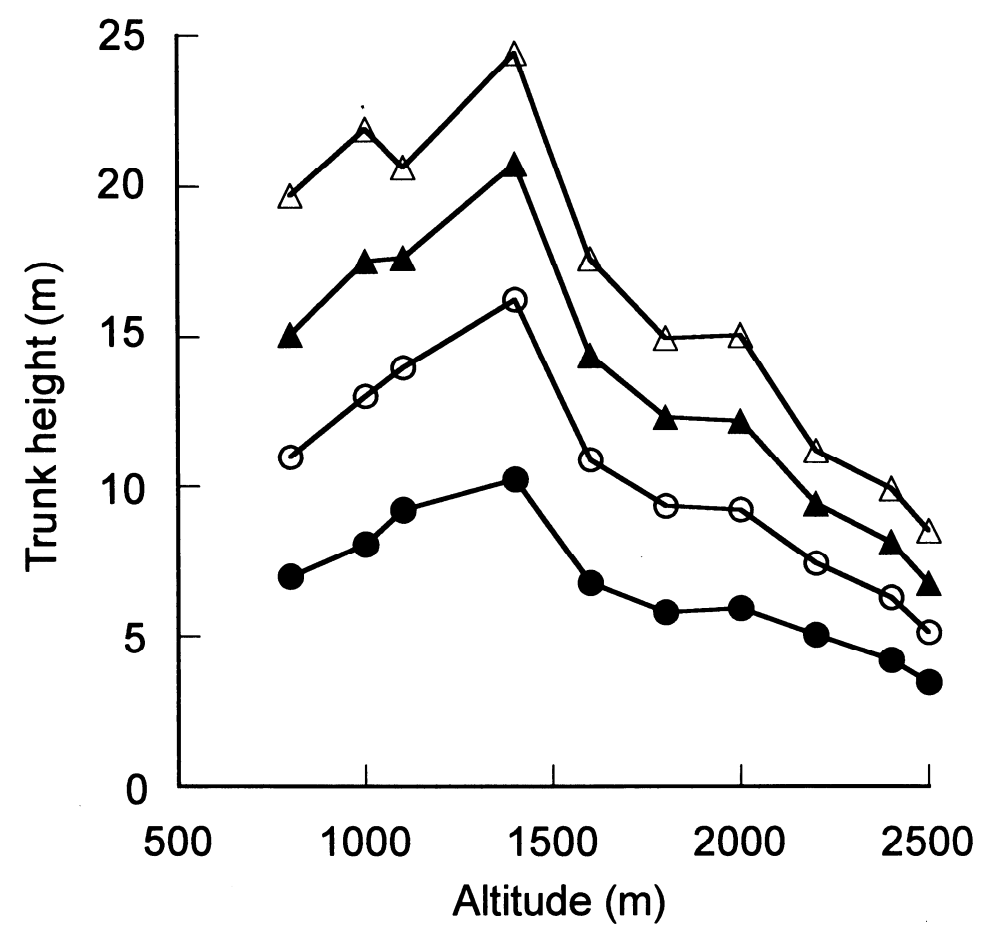

Fig. 3. 

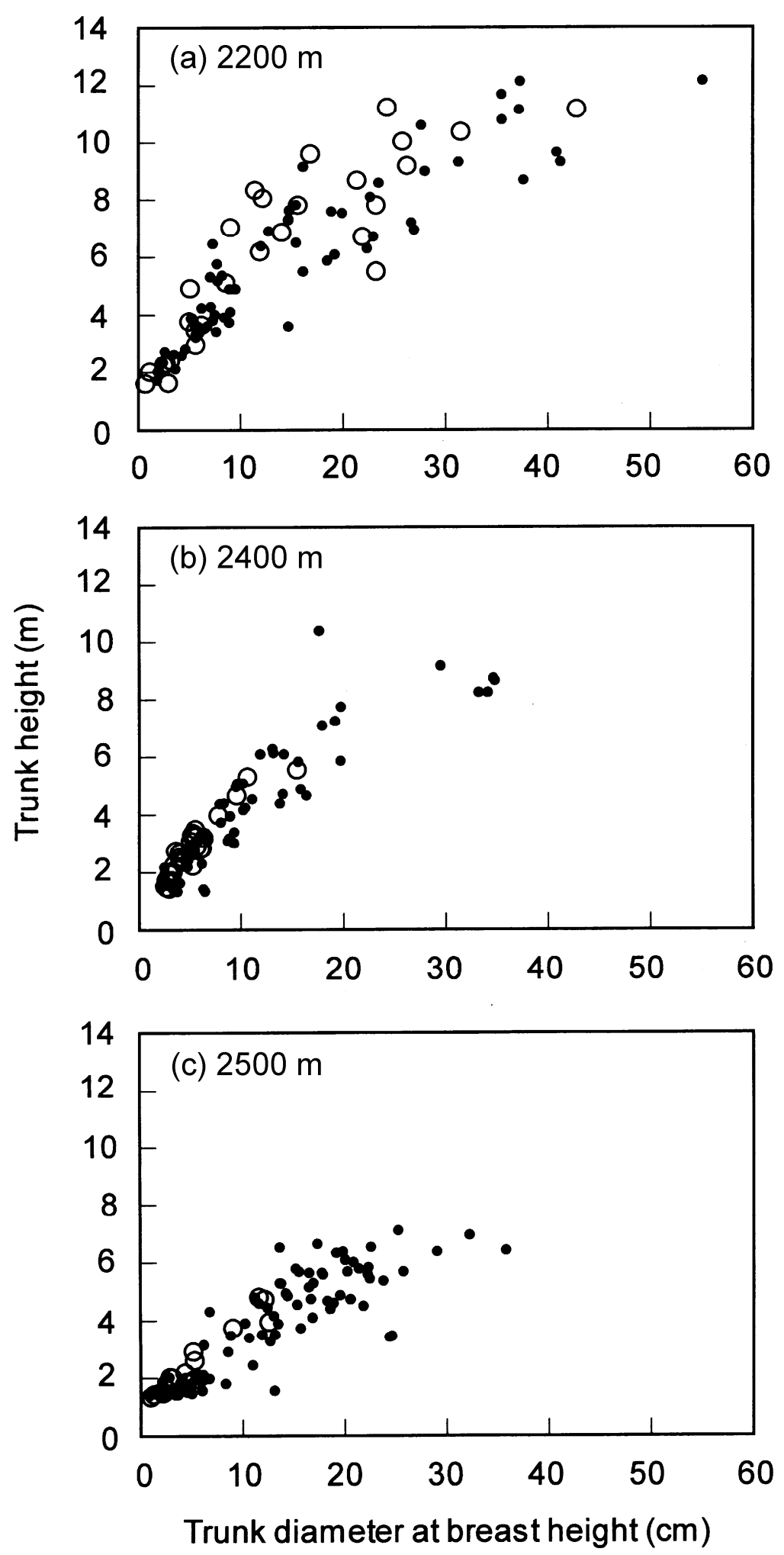

Fig. 4. 